\title{
Porous aerosol in degassing plumes of Mt. Etna and Mt. Stromboli
}

Valery Shcherbakov $^{1,2}$, Olivier Jourdan ${ }^{1}$, Christiane Voigt ${ }^{3,4}$, Jean-Francois Gayet $^{1}$, Aurélien Chauvigne ${ }^{1}$, Alfons Schwarzenboeck ${ }^{1}$, Andreas Minikin ${ }^{3, a}$, Marcus Klingebiel ${ }^{4,5}$, Ralf Weigel ${ }^{4}$, Stephan Borrmann ${ }^{4}$, Tina Jurkat ${ }^{3}$, Stefan Kaufmann $^{3}$, Romy Schlage ${ }^{3}$, Christophe Gourbeyre ${ }^{1}$, Guy Febvre ${ }^{1}$, Tatyana Lapyonok ${ }^{6}$, Wiebke Frey ${ }^{7, b}$, Sergej Molleker ${ }^{7}$, and Bernadett Weinzierl ${ }^{3,8}$

${ }^{1}$ Laboratoire de Météorologie Physique, UMR 6016 CNRS/Université Clermont Auvergne, Clermont-Ferrand, France

${ }^{2}$ LaMP, Institut Universitaire de Technologie d'Allier, Montluçon, France

${ }^{3}$ Institut für Physik der Atmosphäre, Deutsches Zentrum für Luft- und Raumfahrt (DLR), Oberpfaffenhofen, Germany

${ }^{4}$ Institut für Physik der Atmosphäre, Johannes Gutenberg-Universität Mainz, Mainz, Germany

${ }^{5}$ Max Planck Institute for Meteorology, Hamburg, Germany

${ }^{6}$ Laboratoire d'Optique Atmosphérique, UMR 8518 CNRS/Université des Sciences et Technologies de Lille, Villeneuve d'Ascq, France

${ }^{7}$ Max Planck Institute for Chemistry, Particle Chemistry Department, Mainz, Germany

${ }^{8}$ University of Vienna, Faculty of Physics, Aerosol Physics and Environmental Physics, Vienna, Austria

${ }^{a}$ now at: Flugexperimente, Deutsches Zentrum für Luft- und Raumfahrt (DLR), Oberpfaffenhofen, Germany

${ }^{b}$ now at: The University of Manchester, Centre for Atmospheric Science, Manchester, UK

Correspondence to: Valery Shcherbakov (v.shcherbakov@opgc.univ-bpclermont.fr)

Received: 1 March 2016 - Published in Atmos. Chem. Phys. Discuss.: 31 March 2016

Revised: 1 July 2016 - Accepted: 11 August 2016 - Published: 23 September 2016

\begin{abstract}
Aerosols of the volcanic degassing plumes from Mt. Etna and Mt. Stromboli were probed with in situ instruments on board the Deutsches Zentrum für Luft- und Raumfahrt research aircraft Falcon during the contrail, volcano, and cirrus experiment CONCERT in September 2011. Aerosol properties were analyzed using angular-scattering intensities and particle size distributions measured simultaneously with the Polar Nephelometer and the Forward Scattering Spectrometer probes (FSSP series 100 and 300), respectively. Aerosols of degassing plumes are characterized by low values of the asymmetry parameter (between 0.6 and 0.75 ); the effective diameter was within the range of 1.5 $2.8 \mu \mathrm{m}$ and the maximal diameter was lower than $20 \mu \mathrm{m}$. A principal component analysis applied to the Polar Nephelometer data indicates that scattering features of volcanic aerosols of different crater origins are clearly distinctive from angular-scattering intensities of cirrus and contrails. Retrievals of aerosol properties revealed that the particles were "optically spherical" and the estimated values of the real part of the refractive index are within the interval from 1.35 to 1.38 . The interpretation of these results leads to the conclusion that the degassing plume aerosols were porous
\end{abstract}

with air voids. Our estimates suggest that aerosol particles contained about 18 to $35 \%$ of air voids in terms of the total volume.

\section{Introduction}

The impacts of continuously degassing volcanoes on the environment and human health are well recognized (Delmelle, 2003; Mather et al., 2004). Fumarolic plumes of passively degassing volcanos are strongly involved in the deposition and redistribution of metals and trace elements (Fulignati et al., 2006). Degassing volcanoes have a potentially large effect on the natural background aerosol loading and the radiation budget of the atmosphere (Schmidt et al., 2012; Oppenheimer et al., 2011).

The size-resolved chemical composition, morphology, and particle size distribution of volcanic aerosols are important in defining their effects on the atmosphere, environment, and human health. A description of the various techniques used in the characterization of "near-source" volcanic particles as well as a review of field campaign results are given by Mather 
et al. (2004). The morphology of atmospheric and volcanic plume aerosols was studied mostly by electron microscopy and X-ray spectroscopy (see, e.g., Pósfai et al., 1999; Obenholzner et al., 2003; Mather et al., 2004; Martin et al., 2008). Due to the high spatial resolution of such instruments, it was evidenced that complex composition, irregular shape, intricate internal structure, and random surface roughness are the rule rather than the exception for aerosol particles. At the same time, the quasi-spherical particles are not uncommon (see, e.g., Obenholzner et al., 2003).

The overwhelming majority of works dealing with internal structure of aerosol particles consider a mixture of chemical compounds (see, e.g., Nousiainen, 2009; Ulanowski and Schnaiter, 2011, and references therein). To date, literature on porous aerosol is rather limited. Jeong and Nousiainen (2014) demonstrated, using transmission electron microscopy analysis, that the internal structures of individual Asian dust particles were formed by the patterned arrangement of nano-to-micron-sized mineral grains and pores. Highly porous aerosol particles, obtained from proxies for organic compounds, were investigated by Adler et al. (2013, 2014) with focused ion beam - scanning electron microscopy techniques and a cavity ring-down system. Most of the information on volcanic vesicular, i.e., porous ash, particles was obtained from samples collected at the ground level. A compilation of the morphological features of volcanic ash particles derived through the use of scanning electron microscopy was done by Heiken and Wohletz (1985).

Generally, scattering matrices of irregular and/or heterogeneous particles have to be modeled on the base of the exact electromagnetic wave theory (see, e.g., Mishchenko et al., 2000). On the other hand, heterogeneous materials could be treated similarly to homogeneous substances when the typical dimension $d$ of their inhomogeneity is much smaller than the wavelength $\lambda$ of the considered radiation, $d \ll \lambda$ (Chýlek et al., 2000), that is, using effective medium approximations (EMAs). The applicability of EMAs for calculating scattering properties of inhomogeneous atmospheric particles was verified in the recent work by Liu et al. (2014) by comparing it with the standards of truth provided by calculations based on the pseudo-spectral time domain method (PSTD). The exact heterogeneous mixing structures of nonabsorptive or weakly absorptive particles were considered in the PSTD calculations. Liu et al. (2014) concluded that scattering properties of the equivalent homogeneous particles agree well with those of internally mixed particles. Fundamental aspects and recent developments of the scattering of electromagnetic radiation by a discrete random medium as well as applicability of the EMAs are reported in the work by Mishchenko et al. (2016).

Of course, it is hardly probable that EMAs are able to provide all elements of a scattering matrix with high accuracy for any value of the scattering angle $\theta$. But, it is feasible to perform modeling with admissible errors, especially when one deals with angular-scattering intensities within a limited interval of $\theta$. For example, the works by Chýlek et al. (1988) and Kolokolova and Gustafson (2001) showed acceptable agreement between experimental results and EMA calculations.

Remote sensing methods, namely sun photometry, lidar sounding, and satellite observations, are largely employed for volcanic plume studies. Generally, such techniques are related to inverse problems, i.e., retrievals of aerosols characteristics on the base of measured optical signals. Consequently, values of the aerosol refractive index have to be estimated with a retrieval code or specified a priori, i.e., preassigned. When values are preassigned, the refractive index of bulk matter or sulfuric acid solutions are commonly used (see, e.g., Watson and Oppenheimer, 2000, 2001; Spinetti et al., 2003; Kahn et al., 2007; Martin et al., 2009; Marenco et al., 2011; Young et al., 2012). Examples for which the refractive index was retrieved along with a size distribution can be found in the works by Toledano et al. (2012), Waquet et al. (2014), and references therein. Effective medium approximations were used in inverse problems by Abo Riziq et al. (2007) and Adler et al. (2013, 2014) where refractive indices of laboratory-generated aerosols were retrieved by comparing the measured size-resolved extinction efficiency with Mie theory calculations.

This work is devoted to aerosol optical characteristics of degassing plumes, retrievals of size distributions and refractive index values, and consequent inferences about morphological properties of aerosols for the volcanoes Mt. Etna and Mt. Stromboli. In the following, the aircraft instrumentation and the measurement conditions are outlined first. Section 3 addresses the outcomes of the principal component analysis in detail. Section 4 describes a careful approach to derive size distributions and refractive index as well as the results. Section 5 is devoted to discussion and inferences.

\section{Instrumentation and flight overview}

This study addresses in situ measurements in degassing plumes from the volcanoes Mt. Etna and Mt. Stromboli performed during the CONCERT (contrail, volcano, and cirrus experiment) campaign in 2011 (Voigt et al., 2014a). Particles and trace gases of the volcanic plumes were probed with instruments on board the DLR (Deutsches Zentrum für Luft- und Raumfahrt) research aircraft Falcon. Descriptions of the instrumentation of the two CONCERT campaigns in 2008 and 2011 are given in Voigt et al. (2010, 2011, 2014a); individual instruments are discussed in detail by Frey et al. (2011), Gayet et al., (2012), Jeßberger et al. (2013), Kaufmann et al. (2014, 2016), and Jurkat et al. (2016). In addition to the instrumentation of the CONCERT campaign in 2008 (Voigt et al., 2010), the FSSP-100 forward-scattering spectrometer probe was employed during the CONCERT campaign in 2011. Below, we briefly describe the instruments used for our study. 


\subsection{Particle probes}

The Polar Nephelometer (PN) (Gayet et al., 1997) measures the angular-scattering intensities (ASIs) of an ensemble of particles ranging from less than $1 \mu \mathrm{m}$ to about $1 \mathrm{~mm}$ diameter, which intersect a collimated laser beam $(\lambda=804 \mathrm{~nm})$ near the focal point of a parabolic mirror. Observations are usually limited to 32 scattering angles $\theta$ near-uniformly positioned from $15^{\circ}$ to $162^{\circ}$. Measurements at nearly forward and backward directions $\left(\theta<15^{\circ}\right.$ and $\left.\theta>162^{\circ}\right)$ are not reliable due to the diffracted light pollution caused by the edges of holes drilled on the paraboloidal mirror (see, e.g., Jourdan et al., 2010). The sampling volume is defined by the crosssectional area of the beam $(10 \mathrm{~mm}$ long and $5 \mathrm{~mm}$ diameter) multiplied by a linear speed of air populated with particles passing through the instrument. Direct measurement of the ASIs allows particle types (droplets or nonspherical particles) to be distinguished and calculation of the optical parameters to be performed (extinction coefficient Ext and asymmetry parameter $g$, see Gayet et al., 2002). Generally, the $g$ value decreases with increasing nonsphericity of the particles, all other parameters being the same (Gayet et al., 2002, 2012). The accuracies of the extinction coefficient and asymmetry parameter are 25 and $4 \%$ (Jourdan et al., 2010; Gayet et al., 2012).

The FSSP-300 and FSSP-100 forward-scattering spectrometer probes (Baumgardner et al., 1992; Petzold et al., 1997; Frey et al., 2011) measure the intensity of light scattered by single particles in a forward direction at angles from 6 to $15^{\circ}$ (Jeßberger et al., 2013), which is governed mainly by diffraction and therefore depends on (i) the refractive index of the particles, and (ii) the projected area of the particle which itself depends on the particle shape. Indeed, the size calibration for nonspherical particles is expressed in terms of equivalent surface diameter, i.e., the diameter of a sphere that has the same projected area (Mishchenko et al., 1997). The FSSP-300 signal is resolved into an array of 31 channels in the size range of 0.35 to $38.6 \mu \mathrm{m}$. The signal is then converted into a corresponding particle size using water droplet response (the refractive index of 1.33). Because of the ambiguities in the Mie scattering curve, the FSSP-100 size distributions have been rebinned to 14 size bins in the diameter range from 1.02 to $47.05 \mu \mathrm{m}$ (water droplet).

\subsection{Trace gas instruments}

The trace gases $\mathrm{SO}_{2}, \mathrm{HCl}$, and $\mathrm{HNO}_{3}$ were measured by the Airborne chemical Ionization Mass Spectrometer (AIMS) (Voigt et al., 2014a; Jurkat et al., 2016) equipped with an inlet system and a custom-made ion source generating $\mathrm{SF}_{5}^{-}$ reagent ions (Jurkat et al., 2010). Air is drawn into the backward-facing perfluoroalkoxy (PFA) inlet using a pumping system. In the high-voltage gas discharge ion source $\mathrm{SF}_{5}^{-}$ ions are produced from a flow of $\mathrm{SCF}_{8}$ in $\mathrm{N}_{2}$ at pressures controlled to $40 \mathrm{hPa}$. The $\mathrm{SF}_{5}^{-}$ions react selectively with trace species to form product ions via a fluoride transfer reaction (Jurkat et al., 2011). The ions pass three differentially pumped vacuum chambers of the mass spectrometer system, before they are detected with a channeltron detector. An inflight calibration is performed by adding a permanent flux of isotopically labeled ${ }^{34} \mathrm{SO}_{2}$ to the inlet line. Further, $\mathrm{HNO}_{3}$ and $\mathrm{HCl}$ were calibrated in the laboratory after the flights. Accuracies of $17-36 \%$ were achieved for $\mathrm{SO}_{2}, 33-35 \%$ for $\mathrm{HCl}$, and $18-36 \%$ for $\mathrm{HNO}_{3}$, mainly depending on dilution of the inlet flow (Voigt et al., 2014a, b).

Water vapor was measured with the tunable diode laser system WARAN (WAter vapoR ANalyzer), which primarily consists of a commercial WVSS-II water vapor sensor (SpectraSensors Inc.) (Kaufmann et al., 2014) with a measurement range from 30 to $40000 \mathrm{ppmv}$. In the measurement cell, a laser is tuned over the water vapor absorption line at $1.37 \mu \mathrm{m}$ and the water vapor mixing ratio is determined from the absorption signal. The passive sample flow through the system is realized using a Rosemount inlet. The water vapor mixing ratio is measured with a relative uncertainty $<6 \%$ at $2.4 \mathrm{~s} \mathrm{time} \mathrm{resolution} \mathrm{and} \mathrm{for} \mathrm{water} \mathrm{vapor} \mathrm{mixing} \mathrm{ratios} \mathrm{above}$ $500 \mathrm{ppmv}$ relevant for the low-altitude flight legs shown here. The instrument is calibrated before and after the campaign using a frost point hygrometer (MBW373LX) as the reference. The uncertainty of $0.5 \mathrm{~K}$ in the static air temperature measurement translates to a relative uncertainty of around $4 \%$ in the saturation pressure over water. Adding both contributions, the relative humidity with respect to water $\left(\mathrm{RH}_{\mathrm{w}}\right)$ can be determined with a relative uncertainty of a $\mathrm{RH}_{\mathrm{w}}$ value generally less than $10 \%$.

\subsection{Flight overview}

Degassing plumes from the volcanoes Mt. Stromboli and Mt. Etna were probed on 30 September 2011 (from 06:50 to 08:40 UTC). Visual observations from the cockpit of the Falcon showed that there was a single plume degassing from Mt. Stromboli, whereas there were two distinct degassing plumes from Mt. Etna, see Fig. 1a. The Etna plumes were spreading at two different altitudes and they originated from at least two craters, namely Northeast Crater (upper plume) and Bocca Nuova Crater (lower plume) (Voigt et al., 2014a). From the four main craters at Mt. Etna, these two craters were identified as the major emitters on that day. The Falcon flight track over Sicily is shown in Fig. 1b. It was set up to probe the two Etna plumes and the Stromboli plume.

Figure 2 shows time series of trace gases measurements, flight altitude, extinction coefficient, and asymmetry parameter derived from the Polar Nephelometer measurements. The very low relative humidity has to be particularly emphasized. The values of $\mathrm{RH}_{\mathrm{w}}$ are lower than the crystallization humidity of most sulfates, nitrates, and chlorides (see, e.g., Tang and Munkelwitz, 1991). In other words, the plumes were spreading in the dry troposphere. In addition, the air temperatures within the plumes were always above the freezing 


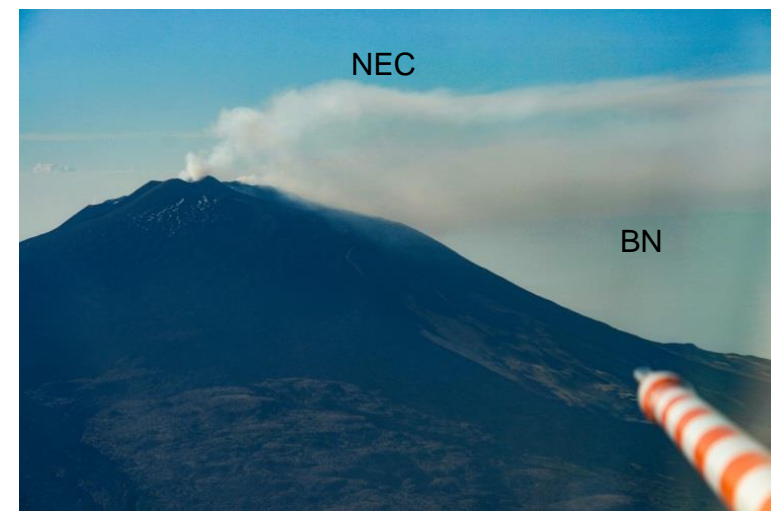

(b)

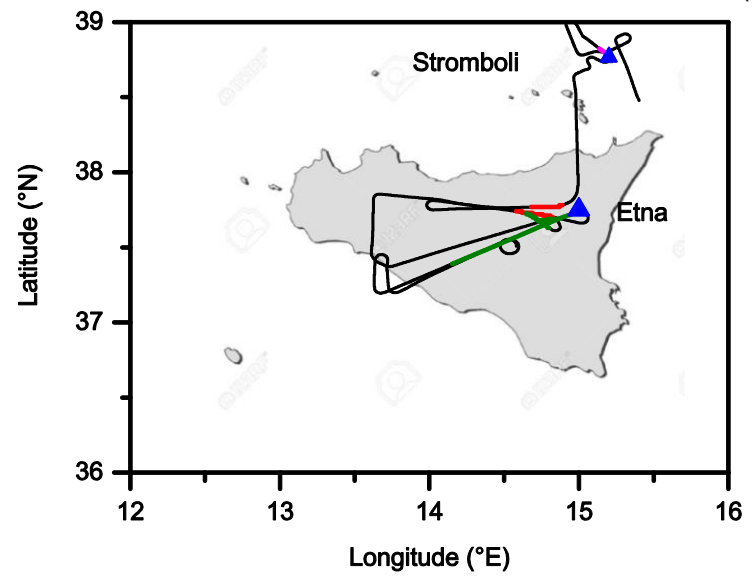

Figure 1. (a) Degassing Etna plumes from Northeast (NEC) and Bocca Nuova (BN) craters as seen from the DLR Falcon Research aircraft (Photo: Bernadett Weinzierl); (b) Falcon flight track over Sicily on 30 September 2011.

point, i.e., $>273.15 \mathrm{~K}$. The extinction coefficient series reveals several peaks that correspond to the time intervals when the research aircraft was probing the degassing plumes (see shaded areas in Fig. 2). The close correspondence between the extinction coefficient and the time series of the trace gases $\mathrm{HNO}_{3}, \mathrm{SO}_{2}, \mathrm{HCl}$ is evident in Fig. 2. The trace gas composition of the volcanic plumes has been investigated by Voigt et al. (2014a). Different trace gas mixing ratios of $\mathrm{CO}_{2} / \mathrm{SO}_{2}$ and $\mathrm{SO}_{2} / \mathrm{HCl}$ have been identified in the volcanic plumes from the Northeast and Bocca Nuova craters. Specifically, it is shown that neither $\mathrm{SO}_{2}$ conversion to sulfate nor $\mathrm{HCl}$ uptake in sulfate aerosol play a major role in the aging plume under dry tropospheric conditions.

\section{PCA analysis of Polar Nephelometer data}

In this section, a statistical tool, the principal component analysis (PCA) is applied to the Polar Nephelometer data obtained during the CONCERT campaign in 2011. It should be emphasized that the peculiarity of the PN data recorded within the quiescent degassing volcanic plumes is that the signals were quite low, at least much lower than those ones registered within contrails and clouds. We recall that during particle samplings, the Polar Nephelometer raw signals are superimposed on the background signals (or zero baselines), which are due to electronic or optical noises. As a consequence, the accurate subtraction of the background signals was of utmost importance (see Shcherbakov et al., 2006). Thus, the corresponding data were preprocessed with special purpose software and operator supervision of the data treatment quality, i.e., wavelet denoising technique.

\subsection{Clustering techniques}

We employed the PCA to carry out the cluster analysis (see, e.g., Jolliffe, 2002, chap. 9; Jourdan et al., 2010), that is, to separate the recorded angular-scattering intensities (ASIs) into clusters. The advantage of the PCA consists of the fact that it is self-sufficient; in other words, no a priori hypotheses are needed, because the clustering is only based on internal properties of a data set. In brief, the PCA is an unsupervised method used to explore the intrinsic variability of the data.

The PCA is particularly fruitful when one deals with highdimensional data. The PCA provides the possibility of capturing much of the total data variation in a few dimensions and organizing observed data into meaningful clusters. That is, with the PCA technique, each vector of the data can be represented adequately by a few coefficients, usually three, which correspond to eigenvectors of a covariation matrix. This is especially true when a limited number of primary physical parameters have a major impact on the measured functions (in our case, angular-scattering intensities). The obtained coefficients can be used in visualization of the data by scatter plots.

Algebraically, principal components could be defined as particular linear combinations of a set of variables. These linear combinations represent the selection of a new coordinate system obtained by rotating the original system of coordinates. The new axes correspond to the directions with maximum variability and provide a simpler description of the covariance structure of the original set of variables (Johnson and Wichern, 1998).

The peculiarity of our approach is that the log transformation is applied to the angular-scattering intensities before the PCA is carried out (see details in Jourdan et al., 2003; Shcherbakov et al., 2005). The reason for such a preprocessing is the following. In contrast to phase functions, ASIs are not normalized, e.g., they are proportional to the particle concentration. In addition, the ASIs values, as well as the variances at the forward angles, as a rule, are of orders of magnitude higher than that ones at the sideward and backward angles. In such conditions, the conventional PCA yields the first principal components that only follow the variance at the forward angles; they do not reproduce all the ASIs 


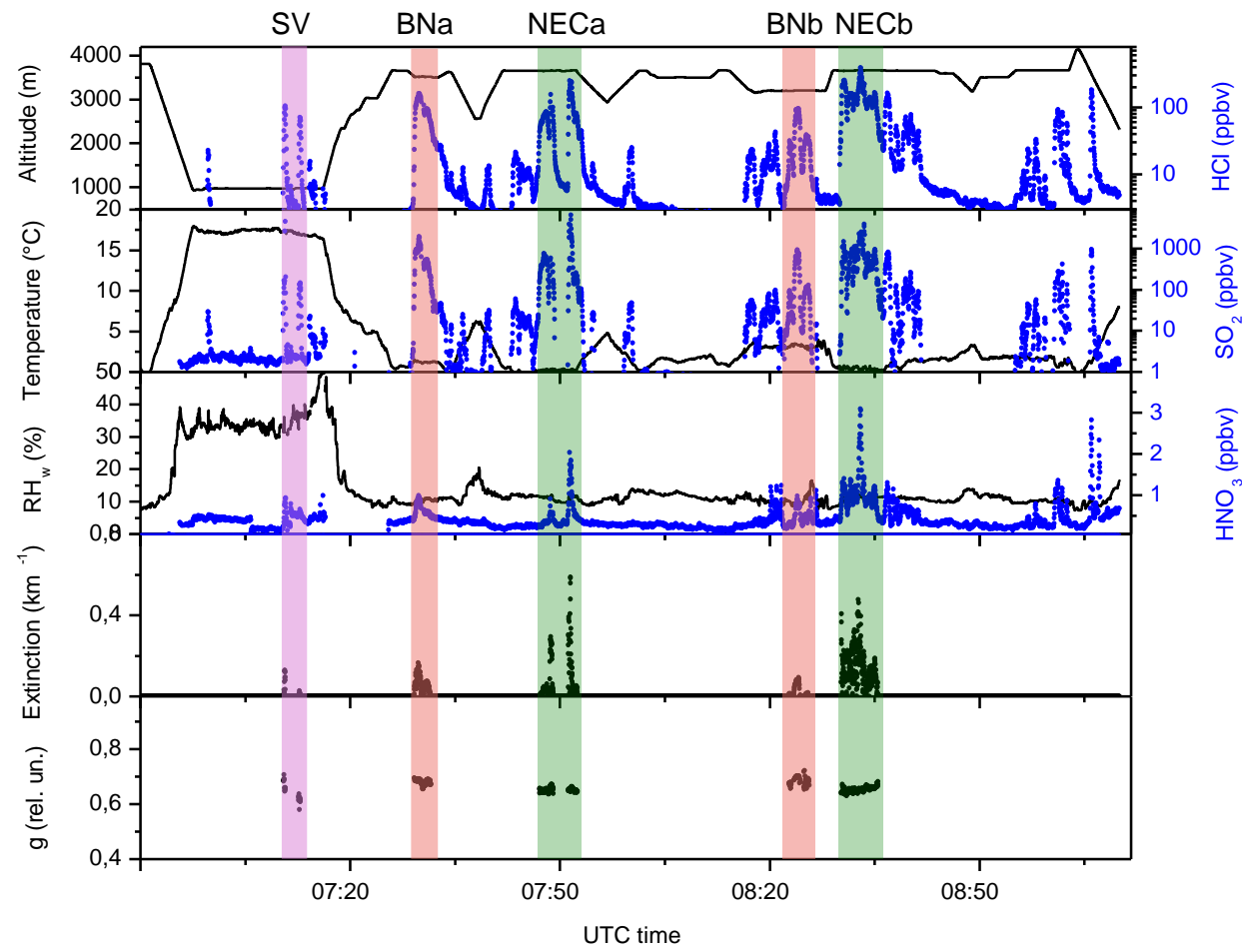

Figure 2. Aircraft observations of Stromboli and Etna plumes on 30 September 2011. Time series of altitude, air temperature $(T)$, relative humidity with respect to water $\left(\mathrm{RH}_{\mathrm{W}}\right)$, extinction coefficient $(\mathrm{Ext})$, and asymmetry parameter $(g)$ are shown by black points. All these parameters are referred to the left-hand $y$ axes. Time series of $\mathrm{HCl}, \mathrm{SO}_{2}$, and $\mathrm{HNO}_{3}$ mixing ratios are shown by blue points and referred to the right-hand $y$ axes. Shaded areas labeled SV, BN, and NEC stand for plume samplings related to Stromboli, Bocca Nuova, and Northeast Etna craters, respectively.

variability. The preprocessing, that is, the logarithm of ASIs values, makes the variances comparable at all angles. In the strict sense, the log transformation leads to the multiplicative model of the variance analysis, in contrast to the conventional PCA, which is based on the additive model. At the same time, the variance can be discussed in terms of the additive model when ASIs are plotted in the log scale.

Expressed mathematically, our approach leads to the following representation of measured angular-scattering intensities $\sigma_{j}\left(\theta_{i}\right)$ in terms of the principal components $\xi_{l}\left(\theta_{i}\right)$, that is, the first $k$ eigenvectors of the correlation matrix of the logtransformed data set:

$\ln \left[\sigma_{j}\left(\theta_{i}\right)\right] \approx\left\langle\ln \left[\sigma\left(\theta_{i}\right)\right]\right\rangle+\sum_{l=1}^{k} C_{j, l} \xi_{l}\left(\theta_{i}\right)$

where $\theta_{i}$ is the scattering angle, the index $i$ designates the $i$ th scattering angle and takes values from 1 to 32 , the index $j$ refers to the $j$ th observation of the analyzed flight sequences, $\langle\ldots\rangle$ denotes averaging over the total data set (i.e., 1803 PN measurements). When vector expressions are employed, $\boldsymbol{\sigma}_{j}$ has the components $\sigma_{j}\left(\theta_{i}\right) ; \boldsymbol{\xi}_{l}, \ln \sigma_{j}$, and $\ln \sigma$ have the components $\xi_{l}\left(\theta_{i}\right), \ln \left[\sigma_{j}\left(\theta_{i}\right)\right]$, and $\left\langle\ln \left[\sigma_{j}\left(\theta_{i}\right)\right]\right\rangle$, respectively. The coefficients $C_{j, l}$ are computed as $C_{j, l}=$ $\left(\ln \sigma_{j}-\langle\ln \sigma\rangle\right)^{T} \cdot \boldsymbol{\xi}_{l}$, where ${ }^{T}$ denotes a transposed matrix.
Each vector (i.e., $\ln \sigma_{j}$ at each $j$ ) is represented by a few coefficients $C_{j, l}$ with quite good accuracy.

\subsection{Clustering results}

The PCA results were obtained using the CONCERT data recorded during the flights on 16 September 2011 (from 14:40 to 17:50 UTC) (Kaufmann et al., 2014) and on 30 September 2011 (from 06:50 to 08:40 UTC) (Voigt et al., 2014a). The data set contains the ASIs measured in degassing plumes, cirrus and contrails. Such a large set was chosen to point out that the scattering pattern of degassing plumes is clearly distinctive (see below).

When the PCA is applied to ASIs, the principal components can have a clear physical meaning. Figure 3 a shows the first three principal components along with the corresponding eigenvalues $\lambda_{l}$ normalized as a percentage of the total variance. The first vector $\xi_{1}$ almost does not depend on the scattering angle, it accounts for $96.8 \%$ of the data variability. This means that it is closely linked to the extinction coefficient and about $97 \%$ of the ASIs variation is mostly due to fluctuations of the particle concentration.

It is well known that effects of size distribution, refractive index, particle shape, and surface roughness are better represented using phase functions, i.e., normalized ASIs. Thus, 

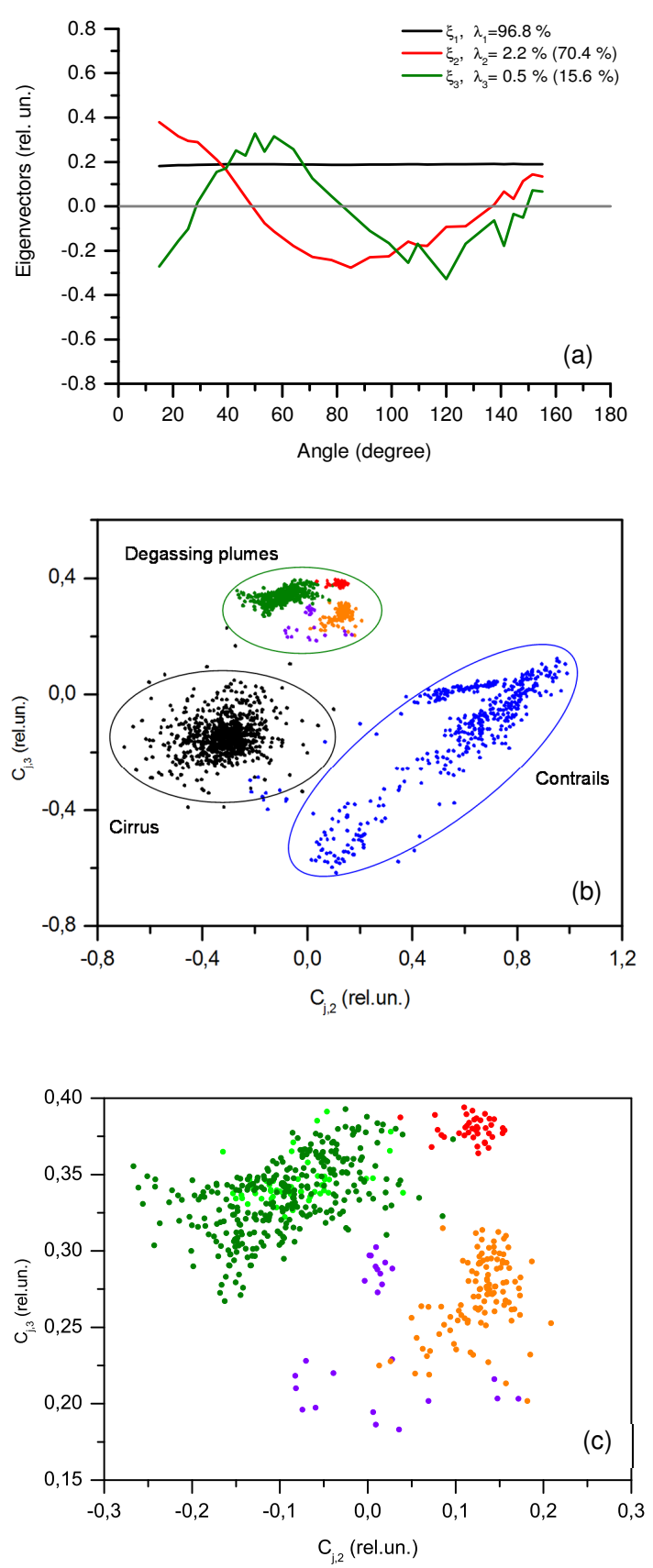

Figure 3. (a) Results of the principal component analysis. First three eigenvectors $\left(\xi_{l}\right.$ stand for $\xi_{l}$ ) of the angular-scattering intensities (ASI) of the correlation matrix vs. measured scattering angles. Values of the first three normalized eigenvalues $\lambda_{l}$ of the eigenvectors and the remaining variability are also displayed. (b) Expansion coefficient diagram: third coefficient vs. second coefficient. Black points for cirrus clouds, blue points for contrails, olive points for the Northeast Crater plume, violet points for Stromboli, orange points for $\mathrm{BNa}$, and red points for BNb crater plumes. (c) Same as (b) but with the focus of attention on the degassing plumes. Green points for NECa and olive points for NECb crater plumes. not only the other principal components are of importance, their contribution to the remaining variability has to be evaluated.

The second vector $\xi_{2}$ represents $70.4 \%$ of the remaining variability; it has negative values at sideward angles. Generally, high negative values of the corresponding coefficients $C_{j, 2}$ of such a vector take into account the irregular shape and/or the deep surface roughness of large particles. All of this leads to lower values of the asymmetry parameter (see, e.g., Jourdan et al., 2010).

The third vector $\xi_{3}$ represents $15.6 \%$ of the remaining variability. Its shape reveals that $\xi_{3}$ is related to the forward/backward-hemisphere partitioning of the scattering. The high negative values of the corresponding coefficients $C_{j, 3}$ imply that less energy is scattered in the forward hemisphere and, thus, more energy is scattered in the backward hemisphere.

Figure $3 \mathrm{~b}$ shows the scatter plot of the $C_{j, 3}$ expansion coefficient vs. the $C_{j, 2}$ coefficient. Therefore, such a presentation describes the features of the PN data set in one of the clearest and most informative ways. Each point is directly associated with one of the measured ASCs. Three main distinctive clusters of points can be identified in Fig. 3b. Additional analysis of the total CONCERT-2011 data set provided the possibility of associating the clusters with the measurements performed within cirrus clouds, contrails, and the degassing volcanic plumes (see the notations in Fig. 3b).

The negative $C_{j, 2}$ values of the cirrus cluster are typical of irregular large ice particles (see, e.g., Jourdan et al., 2010). The contrail cluster is characterized by high positive values of $C_{j, 2}$. This feature means that the corresponding phase functions are quite similar to those of ensembles of large spherical particles. The fraction of spherical particles increases with increasing $C_{j, 2}$. This is especially true for the young contrail subcluster. A detailed discussion can be found in Gayet et al. (2012).

The peculiarity of the degassing plume cluster is that the coefficients $C_{j, 2}$ are close to zero. Thus, the properties of the degassing plume ASIs can be discussed just in terms of the vector $\xi_{3}$. That fact results in the following. The effective diameter and the asymmetry parameter of the degassing plume particles have to be smaller, if not much smaller, compared to those of other clusters in the data set, among them the young contrails. Another property of the degassing plume cluster is that it falls into subclusters. Figure $3 \mathrm{c}$ repeats Fig. $3 \mathrm{~b}$ but with the focus of attention on the degassing plumes. It is seen that the ASIs of the NECa and NECb plumes are close to each other; they form one cluster. The $\mathrm{BNa}$ and $\mathrm{BNb}$ clusters are a little bit separated with the third coefficients, but belong to the same range of the second coefficient that accounts for $70.4 \%$ of the ASIs shape variability. Other properties of the degassing plume subclusters will be discussed in detail below. 


\section{Number concentrations, effective radii and refractive indices of the volcanic plume layers}

In this work the intervals of the degassing-plume penetration were specified on the basis of the PN data after subtraction of the background signals, which correspond to the electronic noise and ASIs of the free atmosphere. The angularscattering intensities (ASI) from the Polar Nephelometer were averaged over the penetration intervals, i.e., over $17 \mathrm{~s}$ for Stromboli (SV) and over 143, 172, 122, 80, and $313 \mathrm{~s}$ for Etna's Bocca Nuova (BNa and BNb) and Northeast (NECa1, $\mathrm{NECa} 2$, and NECb) crater plumes, respectively (see notations in Fig. 1). The averaged ASIs were used to retrieve microphysical and optical characteristics of degassing plume aerosols.

\subsection{Retrieval techniques and software}

Our retrievals were performed with the software and the pre-calculated kernels developed by Dubovik et al. (2006). We recall that the software is employed in the operational processing of AERONET (AErosol RObotic NETwork) for retrieving detailed properties from observations of groundbased sun/sky radiometers (Eck et al., 2008). We will briefly describe the main features of the retrieval algorithm and its implementation on our specific data set.

The pre-calculated kernels contain optical characteristics of spheroids mixtures. The surface of particles can be smooth or severely rough (Yang et al., 2013). A mixture of spheroids of different aspect ratios, sizes and surface texture (smooth or severely rough) is employed as a generalized aerosol model (representing spherical, nonspherical, and mixed aerosols). The aspect ratio values belong to the range (0.3-3.0); the surface-roughness parameter can take only two values 0.0 or 0.2 .

The code offers the possibility of retrieving a complete set of aerosol parameters, including the complex refractive index and the size distribution. The aerosol size distribution is presented using size bins; and the size bins are formed with discrete logarithmically equidistant size values. As for size distribution retrievals, the undoubted advantage of the Dubovik code consists in the fact that solutions are constrained to be nonnegative, which significantly improves the quality of retrievals. The constraint is imposed through an elegant and well-founded approach, more specifically, the assumption of the log-normal distribution of measurement errors (see, e.g., Dubovik et al., 2011).

The code includes a quite large set of input parameters that is very advantageous for an experienced user. For example, for different hypotheses of aerosol composition, among others, effects of the ultrafine fraction can be tested. On the one hand, supervised retrievals are time consuming; on the other, one has the possibility to assure a high quality of retrievals. We list some criteria of the retrieval quality in the following. Final results are scarcely affected by small variations of input parameters. When the regularization-parameter value is chosen according to the "L-curve" method (see, e.g., Hansen, 1992), the retrieval residuals correspond to the measurement errors. In a generally nonlinear case, particular attention must be given to the verification if the obtained solution corresponds to the global minimum of an objective function. As for aerosol characteristic retrievals, different starting values of the refractive index may be randomly tried.

Summarized, we modeled the degassing plumes as a mixture of two main particle fractions; one consists of spherical and one of nonspherical particles. Although aerosol particles were not ellipsoidal, we consider randomly oriented spheroids as a reasonable approximation of an ensemble of quite small nonspherical aerosols. In addition, we recall that we considered smooth and severely rough particles (Yang et al., 2013).

Details of the software package used in this works, as well as the code application are described in the supplementary material. To summarize briefly, different initial guesses for the inversion code were performed on a multidimensional grid of the input parameters using a number of input files. The minimum and the maximum sizes of particles as well as the spherical/nonspherical partitioning ratio belong to the set of assessed parameters in addition to the refractive index and the size distribution.

\subsection{Retrieval results}

Three representative examples of retrievals are shown in Fig. 4. The corresponding time sequences $\mathrm{SV}, \mathrm{BNa}$ and $\mathrm{NECb}$ are identified in the time series in Fig. 2 by shadowed areas. In Fig. $4 \mathrm{a}-\mathrm{c}$, the left panels display the particle size distributions measured with the FSSP-300 and FSSP100 (solid lines) and the retrieved one (solid black circles). It should be pointed out that the FSSP measurements in Fig. 4 represent particle size distributions considering the size response to water droplets. Due to size response uncertainties linked to different refractive indexes and/or particle shape in plume aerosols (Pinnick and Auvermann, 1979; Dye and Baumgardner, 1984; Jaenicke and Hanusch, 1993; Febvre et al., 2012), the comparison with retrieved size distributions should only be considered qualitative in Fig. 4. Despite these limitations, the FSSP data and the retrieved distributions reveal very similar features of the degassing plume aerosols, in particular the absence of large particles. The calibrated probe response of the specific FSSP adjusted to different refractive indexes is beyond the scope of this paper.

The size distribution was retrieved along with the refractive index $m=n+i \chi$ and the spherical/nonspherical partitioning ratio (SNR) of aerosol particles (see Table 1). In the following, the SNR defines the percentage in number of spherical particles relative to the total number of particles. Furthermore, the refractive index and the partitioning ratio are assumed to be constant over the full size range of the retrieved particle size distribution. We emphasize that 

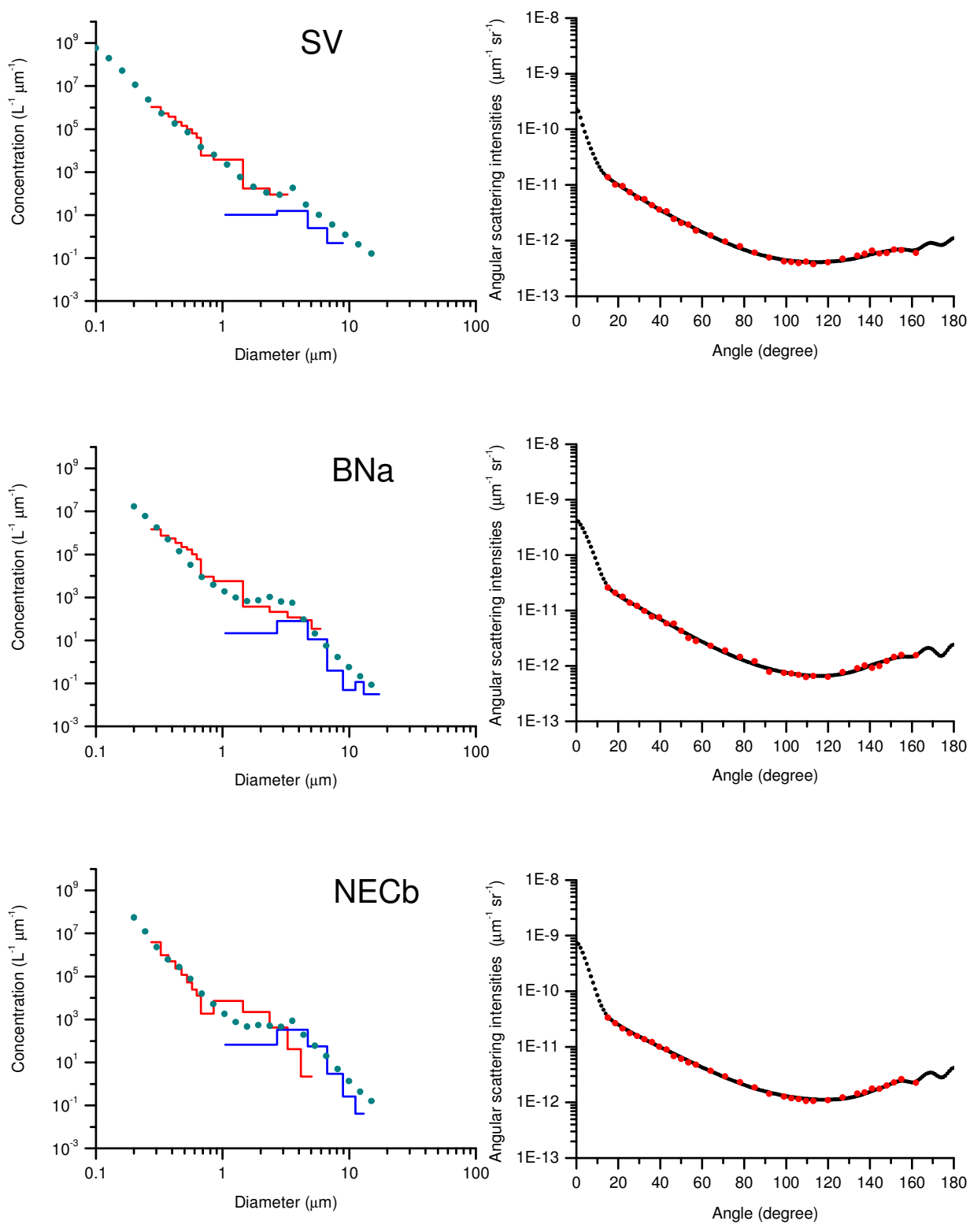

Figure 4. Measured (solid lines) and retrieved (solid black circles) aerosol size distributions (left panels). Measured (solid red circles) and reconstructed (solid black circles) angular-scattering intensities (right panels). Stromboli (top), Bocca Nuova (middle), and Northeast (bottom) Etna craters plums, respectively. (See notations in Fig. 2.)

the information content of the PN data is inadequate for retrieving size-dependent values of such parameters. In other words, variations of the shape and/or the refractive index of small particles lead to variations of the phase function that are lower than the PN measurement errors. Therefore, the refractive index and the partitioning ratio are assumed to be constant over the full size range.

The following results are especially noteworthy. The real part $n$ of the refractive index belongs to the interval from 1.35 to 1.38 ; the aerosol particles were either nonabsorbing or weakly absorbing; the SNR values are equal to $100 \%$, i.e., the best fits of the Polar Nephelometer data were obtained with the model of spherical particles (Table 1).

The assessed value of the maximal particle diameter is about $15 \mu \mathrm{m}$ for the all degassing-plume penetrations (Fig. 4). That is, the size parameter of the probed aerosols is rather small (lower than 60 for the wavelength of $0.8 \mu \mathrm{m}$ ). This feature can explain the fact that all our retrieval results were very close for both values of the surface-roughness parameter. The PN measurements are not sensitive enough to distinguish whether small particles have smooth or rough surface. In view of this result and the SNR values, the degassingplume aerosols are assumed to be smooth spheres. 
Table 1. Mean parameter values in the indicated time intervals (see Fig. 1). The parameters are time interval, altitude, air temperature $T$, relative humidity with respect to water $\left(\mathrm{RH}_{\mathrm{w}}\right)$; concentration $(\mathrm{Conc})$ of particles $(d>0.9 \mu \mathrm{m})$, and effective diameter $D_{\text {eff }}$ measured with the FSSPs; real $n$ and imaginary $\chi$ part of the refractive index, spherical/nonspherical partitioning ratio (SNR), asymmetry parameter $g$, extinction coefficients (Ext), and residual (Res) estimated from the retrievals data. (See notations in Fig. 2.)

\begin{tabular}{|c|c|c|c|c|c|c|c|c|c|c|c|c|}
\hline & $\begin{array}{l}\text { UT } \\
\text { (h:min:s) }\end{array}$ & $\begin{array}{r}\text { Alt.) } \\
(\mathrm{m})\end{array}$ & $\begin{array}{r}T \\
\left({ }^{\circ} \mathrm{C}\right)\end{array}$ & $\begin{array}{r}\mathrm{RH}_{\mathrm{W}} \\
(\%)\end{array}$ & $\begin{array}{r}\text { Conc } \\
\left(\mathrm{cm}^{-3}\right)\end{array}$ & $\begin{array}{r}D_{\text {eff }} \\
(\mu \mathrm{m})\end{array}$ & $n$ & $\chi$ & $\begin{array}{r}\text { SNR ) } \\
(\%)\end{array}$ & $g$ & $\begin{array}{r}\text { Ext } \\
\left(\mathrm{km}^{-1}\right)\end{array}$ & $\begin{array}{l}\text { Res. } \\
(\%)\end{array}$ \\
\hline SV & $\begin{array}{l}7: 10: 28 \\
7: 10: 45\end{array}$ & 970 & 17.2 & 36 & 32 & 2.8 & 1.35 & 0 & 100 & 0.65 & 0.056 & 6.5 \\
\hline $\mathrm{BNa}$ & $\begin{array}{l}7: 29: 10 \\
7: 31: 33\end{array}$ & 3518 & 1.2 & 10 & 51 & 1.9 & 1.36 & 0 & 100 & 0.69 & 0.059 & 7.8 \\
\hline $\mathrm{BNb}$ & $\begin{array}{l}8: 22: 45 \\
8: 25: 37\end{array}$ & 3202 & 3.4 & 10 & 25 & 1.5 & 1.37 & 0 & 100 & 0.70 & 0.020 & 9.4 \\
\hline NECa1 & $\begin{array}{l}7: 47: 03 \\
7: 49: 05\end{array}$ & 3656 & 0.3 & 11 & 40 & 2.2 & 1.36 & 0 & 100 & 0.66 & 0.059 & 6.7 \\
\hline NECa2 & $\begin{array}{l}7: 51: 10 \\
7: 52: 30\end{array}$ & 3645 & & & & & 1.38 & 0 & 100 & 0.65 & 0.120 & 7.4 \\
\hline $\mathrm{NECb}$ & $\begin{array}{l}8: 30: 13 \\
8: 35: 30\end{array}$ & 3655 & 0.4 & 10 & 32 & 2.3 & 1.38 & 0 & 100 & 0.66 & 0.075 & 5.7 \\
\hline
\end{tabular}

The right panels of Fig. $4 \mathrm{a}-\mathrm{c}$ represent the following data. The average scattering phase function (without normalization) measured by the Polar Nephelometer is shown by solid red circles (see the averaging time intervals in Table 1). The retrieved phase function, shown by solid black circles, was computed from the retrieved size distribution. The main result of Fig. 4 is that the retrieved phase functions agree well with the observations. It should be underscored that there is no systematic bias between them. In other words, the measured ASIs are well fitted by the retrieved phase functions. The residuals (Res) were computed with the formula

Res $=100 \cdot \sqrt{\frac{1}{N} \sum_{i=1}^{N}\left[\frac{I\left(\theta_{i}\right)_{\mathrm{ret}}-I\left(\theta_{i}\right)_{\text {meas }}}{I\left(\theta_{i}\right)_{\text {meas }}}\right]^{2}}$,

where $I\left(\theta_{i}\right)$ is the light intensity at the scattering angle $\theta_{i}$, and the subscripts "meas" and "ret" refer to the measured and retrieved values, respectively. The low values of the residuals are noteworthy as well, see Table 1.

Table 1 summarizes the measured and retrieved characteristics. As mentioned above, the relative humidity $\mathrm{RH}_{\mathrm{w}}$ was low, i.e., about $36 \%$ within the Stromboli plume and near $10 \%$ during the Etna plume samplings. The air temperature was positive, including at the Etna upper-plume altitude $\left(0.3^{\circ} \mathrm{C}\right)$. The number concentration (Conc) of aerosols with the diameter $d>0.9 \mu \mathrm{m}$ is estimated within the range of 25$51 \mathrm{~cm}^{-3}$. The effective diameter $\left(D_{\text {eff }}\right)$ was low, between 1.5 and $2.8 \mu \mathrm{m}$, where both parameters Conc and $D_{\text {eff }}$ were deduced from the FSSP data. The retrieved values of the refractive index belong to the interval from 1.35 to 1.38 . Low values [0.65-0.70] of the asymmetry parameter $g$ correspond to ensembles of small particles, which is in agreement with the $D_{\text {eff }}$ values. The extinction coefficients Ext were computed from the retrieval data and the values are quite small,

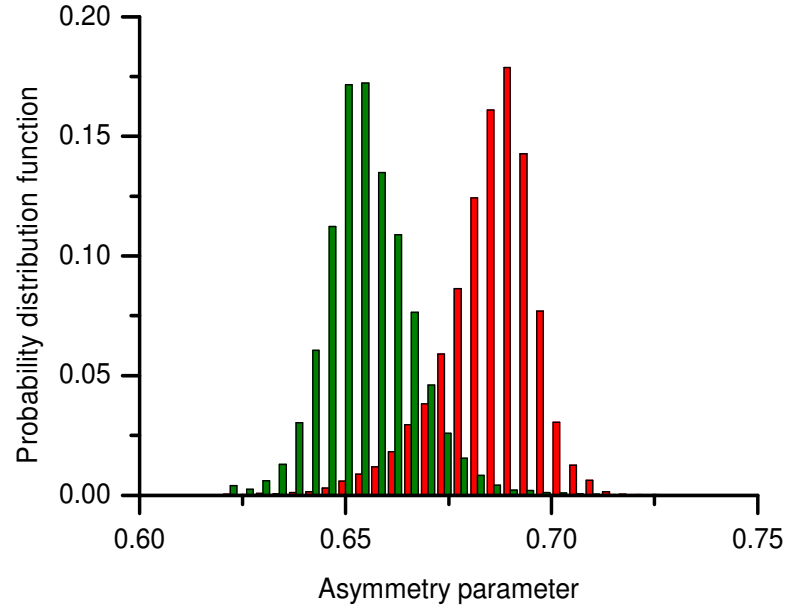

Figure 5. Probability distribution functions of the asymmetry parameter. Bocca Nuova (BNa, red) and Northeast (NECb, green) Etna craters plums, respectively. (See notations in Fig. 2.)

confirming that the ASIs were recorded in single-scattering conditions. We recall that the optical characteristics correspond to the wavelength of $0.8 \mu \mathrm{m}$ and that the all parameters were recorded at distances of more than $6 \mathrm{~km}$ from the plume sources.

As mentioned above, the ASIs of the degassing plumes are partitioned into subclusters (see Fig. 3c). The ASIs of the NECa and NECb plumes are spread within a cluster that is well distinguished from other ones. The second coefficients $C_{j, 2}$ of the $\mathrm{BNa}$ and $\mathrm{BNb}$ data are within the same range of values. (We recall that the second vector $\xi_{2}$ represents $70.4 \%$ of the ASIs shape variability.) Consequently, the asymmetry-parameter values of the Bocca Nuova plumes $(\mathrm{BNa}$ and $\mathrm{BNb})$ are a little bit higher compared to those of 
the Northeast Crater (NECa1, NECa2, NECb), see Table 1. The histograms in Fig. 5 show probability distribution functions of the asymmetry-parameter values computed from the measured ASIs of the BNa and NECb plumes. These two distributions were selected only by using larger data sets, i.e., higher statistical significance. Generally speaking, the $\mathrm{BNb}$ and NECa distributions are close to histograms of the $\mathrm{BNa}$ and NECb, respectively. As seen in Fig. 5, the distributions are narrow, suggesting quite homogeneous aerosol plume properties. The distinction between optical characteristics of the BN and NEC plumes could result from the difference in chemical composition of aerosols (Voigt et al., 2014a). Though completely independent, this classification of the individual volcanic plumes is similar to results from trace gas composition measurements of Voigt et al. (2014a) for plumes $\mathrm{SV}, \mathrm{BNb}, \mathrm{NECa}$, and NECb. In addition, the difference in the $\mathrm{BN}$ and NEC aerosol emissions was underscored earlier by Allen et al. (2006), who studied aerosol particles at the summit of Mt. Etna downwind from the degassing vents, and by Scollo et al. (2012), who reported observations of the Multiangle Imaging SpectroRadiometer. Martin et al. (2008) evidenced persistent differences in the size distributions of sulfate aerosols between the two main Etna summit plumes.

\section{Discussion and inferences}

Our results in Table 1 show that the spherical/nonspherical partitioning ratio (SNR) value is of $100 \%$ for the all considered cases of degassing plumes. In other words, the best fits of the Polar Nephelometer data were obtained with the model of spherical aerosol particles. It must be emphasized that this result does not mean that aerosols were perfect spheres. Since (i) the aerosol particles were quite small with respect to the wavelength of $0.8 \mu \mathrm{m}$ (see the effective diameter values in Table 1), (ii) the angular-scattering intensities (ASIs) were measured within the limited range of angles for the relatively small number of $\theta_{i}$, (iii) the ASIs were averaged over an ensemble of particles, and (iv) the PN data were affected by measurement errors, we only can conclude that the aerosols of the degassing plumes were optically spherical (see, e.g., Dick et al., 1998). The term "optically spherical" should be considered within the context of optical instrumentation. For example, the model of spherical particles matches well the PN experimental data, and we believe that the asymmetryparameter estimates are trustworthy. At the same time, it might be that polarization measurements, particularly in the backward hemisphere, will reveal nonspherical features of degassing plume aerosols.

The retrievals indicate that the aerosol particles were either nonabsorbing or weakly absorbing with an upper bound for the imaginary part of the refractive index of $10^{-4}$. Variations of the phase functions for the imaginary part within the interval $\left[0 ; 10^{-4}\right]$ are smaller than the measurement errors (Verhaege et al., 2008).
The most important and somewhat unexpected result of this work is the fact that the retrieved values of the real part $n$ of the refractive index belong to the interval from 1.35 to 1.38 (Table 1).

Degassing plume aerosols of Mt. Etna were probed at distances greater than $6 \mathrm{~km}$ from the sources, i.e., the volcanic craters. The recorded values of the horizontal air speed at the flight altitudes were $5.9 \mathrm{~m} \mathrm{~s}^{-1}$ or lower. Consequently, our measurements are related to aerosols that were generated more than $16.5 \mathrm{~min}$ earlier. Large aerosols tend to settle quickly out of the atmosphere. High initial concentrations of fine particles decay rapidly in the atmosphere due to coagulation and dilution, so that measurements depend on the distance from the source and the wind conditions (Ammann and Burtscher, 1990). Thus, it is hardly possible to directly compare our in situ data and characteristics of particles sampled on filters at the ground. Nevertheless, some ideas on the chemical composition of degassing plume aerosols can be drawn from published results.

Electron microscopy analysis of particles in the range of diameters 5-100 nm showed significant levels of silicate nanoparticles in Mt. Etna plumes (Ammann and Burtscher, 1990; Martin et al., 2008). As mentioned above, the Dubovik code provides the possibility of evaluating the effects of the ultrafine fraction, i.e., nanoparticles, on retrieval results. Our simulations and tests led us to the following conclusions. The information content of the PN data is inadequate for a correct estimation of the ultrafine-fraction number concentration. Variations of that number concentration within a large range of values do not affect the retrieved values of the refractive index.

According to chromatographic analysis of ionic species of soluble particles sampled on filters from degassing plumes near the crater rims of Mt. Etna (Allen et al., 2006; Martin et al., 2008), aerosols are mainly composed of sulfates. Fluorides, chlorides, and nitrates are present as well. Besides, silicates were observed in Etna degassing plumes (Lefevre et al., 1986; Martin et al., 2008). Generally, the values of the bulk refractive index at $\lambda=0.8 \mu \mathrm{m}$ of sulfates, and other soluble inorganic species presumed to form the degassing plumes belong to the interval $1.48-1.58$ or higher (see, e.g., Toon et al., 1976; Tang, 1996; Lide, 2010). The exception is some alkali halides with $n$ about 1.40 or lower. For example, the refractive index values at $\lambda=0.8 \mu \mathrm{m}$ of $\mathrm{NaF}, \mathrm{KF}$, and $\mathrm{MgF} 2$ are $1.323,1.36$, and 1.375 , respectively $(\mathrm{Li}, 1976)$. As for silicate particles, they have quite large values of the bulk refractive index, e.g., $n$ is about 1.46 for amorphous silica glass (see, e.g., Kitamura et al., 2007), 1.52-1.59 or higher for feldspars (Lide, 2010), and about 1.56-1.99 or higher for garnets and other silicate minerals (Lide, 2010).

It is obvious that the retrieved values $n$ (Table 1) are substantially lower than the bulk refractive index of sulfates and other inorganic matter presumed to form the degassing plumes. That result was thoroughly verified. The Dubovik code provides the possibility of holding a fixed refractive in- 


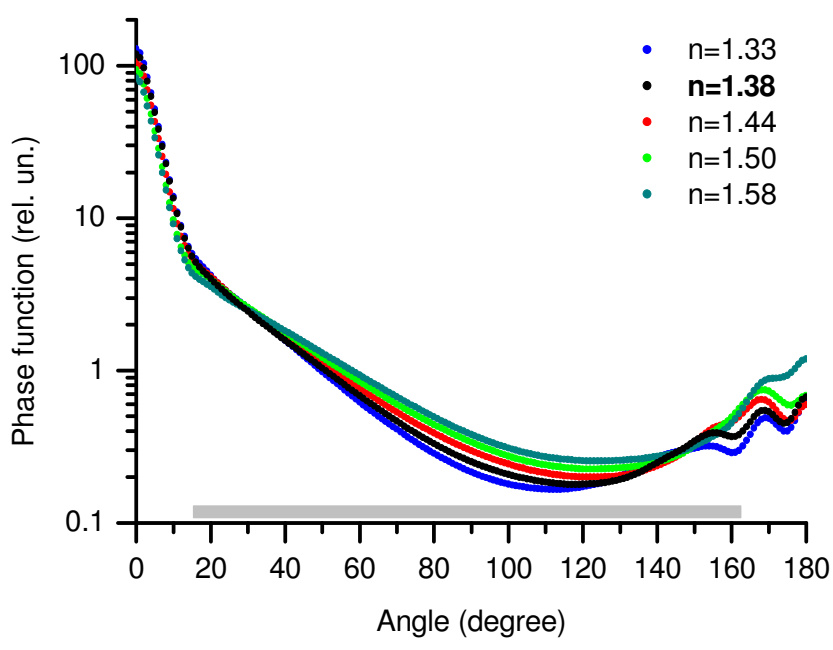

Figure 6. Refractive index dependence of phase functions. The range of the Polar Nephelometer operating angles is indicated by the gray bar.

dex value $n_{\text {fix }}$ while a size distribution is retrieved, and to compute scattering characteristics for given optical constants and the retrieved size distribution. As expected, the residuals Res increased when the fixed value $n_{\mathrm{fix}}$ of the refractive index deviated from the retrieved one. Two important points are to be underscored. When $n_{\text {fix }}$ was higher than 1.40, (i) the Res values significantly exceeded the measurement error level, (ii) the plots of the reconstructed angular-scattering coefficients, that is, computed for $n_{\text {fix }}$ and the corresponding size distribution, clearly manifested a systematic deviation from the plots of the measured ASIs. An illustration of the systematic deviation is given in Fig. 6. The phase functions, i.e., the normalized ASIs, were computed for the retrieved size distribution of the NECb case (see Fig. 4) and a set of values of the real part $n$ of the refractive index. It is seen that the behavior of the curves within the scattering-angles interval of $15-150^{\circ}$ is sensitive to the $n$ value. Not only the slopes of the curves are different but the local minimum shifts monotonically from $114^{\circ}(n=1.33)$ to $124^{\circ}(n=1.58)$. The gray bar in Fig. 6 indicates the range of the PN operating angles. Thus, we can say that the accuracy of the refractive index estimation is based on the functional behavior of measured ASIs. That conclusion corroborates the results of sensitivity tests performed by Verhaege et al. (2008) for ASIs measured within a limited range of scattering angles. It was shown that despite the absence of aureole and backward measurements the real part of the refractive index and the microphysical parameters can be retrieved in the case of the low absorbing particles.

It is unlikely that the relative concentration of alkali halides increased at distances greater than $6 \mathrm{~km}$ from the sources so that their optical properties became dominant. In our particular case, the hypothesis of aqueous solutions or suspensions in the Mt. Etna plumes has to be rejected as well because of the very low relative humidity at the flight altitudes (Table 1). The measured $\mathrm{RH}_{\mathrm{w}}$ values (about $10 \%$ ) are much lower than the efflorescence $\mathrm{RH}_{\mathrm{w}}$ of the overwhelming majority of the abovementioned chemical species (see, e.g., Table 3, Martin, 2000). We recall that efflorescence is a specific process in the more encompassing concept of crystallization; it specifically involves water vapor (Martin, 2000). In other words, the conditions were favorable even for homogeneous nucleation. As for the chemical systems $\mathrm{NaNO}_{3} / \mathrm{H}_{2} \mathrm{O}, \mathrm{NH}_{4} \mathrm{HSO}_{4} / \mathrm{H}_{2} \mathrm{O}$, and $\mathrm{NH}_{4} \mathrm{NO}_{3} / \mathrm{H}_{2} \mathrm{O}$ that do not readily crystallize at the lowest $\mathrm{RH}_{\mathrm{w}}$ values (Martin, 2000), the conditions were favorable for heterogeneous nucleation due to significant levels of silicate nanoparticles in the Mt. Etna plumes (Martin et al., 2008). The hypothesis of unsteady state conditions was discarded in view of the data of the PCA analysis. For example, the NECb plume was probed at distances from the craters between 5.9 and $47.7 \mathrm{~km}$, respectively. Such distances correspond to the aerosol age between $16.5 \mathrm{~min}$ and $2 \mathrm{~h}$. There is no trend in $g$ values of the NECa plume. A slight rise at the end of the NECb $g$ series may be due to increased measurement errors at low aerosol concentrations.

In view of the results above, the most reasonable conclusion to make is that the aerosol particles of the degassing plumes were porous with air voids. Therefore, the retrieved values $n$ (Table 1) correspond to the refractive index of the effective medium instead of the bulk one.

That conclusion is in agreement with data of transmission electron microscopy of aerosol particles collected in the remote marine troposphere (Pósfai et al., 1999). Figure 3a by Pósfai et al. (1999) is especially noteworthy. It shows a quasi-spherical ammonium-sulfate aerosol particle of about $1 \mu \mathrm{m}$ diameter. The particle has the onion-like structure with soot inclusions. Obenholzner et al. (2003) investigated the micromorphology of aerosol particles from the passively degassing plume of Popocatepetl volcano using the Field emission scanning electron microscopy (FESEM). A large set of spherical particles were observed, including spongy, i.e., porous aerosols and spheres, enclosing a dozen small crystals Obenholzner et al. (2003). Moreover, porosity could be the cause of the quite low values of the refractive index of the Eyjafjallajökull volcanic aerosol retrieved from POLDER/PARASOL measurements (Waquet et al., 2014).

Microwave analog experiments performed by Kolokolova and Gustafson (2001) corroborate our conclusion as well. The measured ASIs of inhomogeneous particles show reasonable agreement with effective medium approximations (Kolokolova and Gustafson, 2001). The effective medium approximation (EMA), along with the Maxwell Garnett mixing rule, has already been used in a number of works to calculate optical properties of porous particles (see, e.g., Voshchinnikov et al., 2007; Kylling et al., 2014). The question of EMA applicability is discussed in detail by Mishchenko et al. (2016). 
At a wavelength of $0.8 \mu \mathrm{m}$, the real part of the bulk refractive index of sulfates, nitrates, and other inorganic matter presumed to form the degassing plumes belongs to the range of about $1.48-1.58$. As for the imaginary part $\chi$, it is very small, i.e., lower than $10^{-6}$ at the wavelength of $0.8 \mu \mathrm{m}$ (see, e.g., Gosse et al., 1997). We recall that the aerosol particles are found to be either nonabsorbing or weakly absorbing according to our retrievals. Thus, we assumed that $\chi=0.0$ in the following estimations.

Considering the range of [1.48-1.58], we employed the Maxwell Garnett mixing rule (Maxwell Garnett, 1904; see also Kolokolova and Gustafson, 2001) to estimate the volume fraction $f$ of the inorganic matter that leads to the refractive index of the mixture about [1.35-1.38]. In other words, the inorganic matter and the air voids were taken as the matrix and the inclusions, respectively. We have obtained the interval of [0.65-0.82] as the estimate for the volume fraction value. This means that aerosol particles of the degassing plumes contained $18-35 \%$ of air voids (in terms of the total volume). The estimated volume fraction $f$ and the bulkrefractive index range of inorganic matter would lead to the refractive index of aerosols about [1.43-1.53] if pores were filled up with water. The last assessment is in agreement with the results by Waquet et al. (2014).

Our finding has the following consequences. (i) Climate models, optical methods of remote sensing and optical instruments of particles counting have to consider not the bulkbut the effective refractive index of volcanic particles and aerosols in general. (ii) The volume fraction $f$ of bulk matter has to be taken into account in assessing the volcanic ash spreading and loading. (iii) The volume fraction $f$ has to be considered in aerosol sizing instrumentation based on the inertial separation. (iv) Aerosols porosity could be of importance for condensation and freezing processes.

\section{Conclusions}

Volcanic degassing plumes were probed on 30 September 2011 with in situ instruments onboard the DLR Falcon research aircraft during the CONCERT experiment. The plumes were spreading in the dry troposphere at temperatures above the freezing point.

Aerosols of degassing plumes from the volcanoes Mt. Etna and Mt. Stromboli are characterized by quite low values of the asymmetry parameter (between 0.6 and 0.75 ); their scattering features are clearly distinctive from angular-scattering intensities of cirrus and contrails.

The measured and the retrieved size distributions of the degassing plume aerosols are in good agreement. The effective diameter of the aerosols was within the range of $1.5-2.8 \mu \mathrm{m}$, the maximal diameter of particles was lower than $20 \mu \mathrm{m}$.

Retrievals of aerosol properties revealed that the particles were optically spherical; the estimated values of the real part of the refractive index belong to the interval from 1.35 to
1.38 , which is substantially lower than the bulk refractive index of sulfates, nitrates, and other inorganic matter presumed to form the degassing plumes.

That property leads to the conclusion that the aerosol particles of the degassing plumes were porous with air voids. Our estimates, based on the Maxwell Garnett mixing rule, suggest that aerosol particles of the degassing plumes contained $18-35 \%$ of air voids in terms of the total volume.

\section{Data availability}

The data from this study can be obtained by contacting the corresponding author of this article.

\section{The Supplement related to this article is available online at doi:10.5194/acp-16-11883-2016-supplement.}

Acknowledgements. We thank the DLR flight department for excellent support during the CONCERT campaign. The campaign was organized by the Research Group AEROTROP under HGF contract VH-NG-309. Part of this work is funded by the Research Cluster VAMOS at Johannes Gutenberg University, Mainz and by the German Science Foundation DFG within SPP1294 HALO. J.-F. Gayet is grateful to DLR for having provided a guest scientist opportunity at the Institut für Physik der Atmosphäre during this study.

Edited by: A. Petzold

Reviewed by: two anonymous referees

\section{References}

Abo Riziq, A., Erlick, C., Dinar, E., and Rudich, Y.: Optical properties of absorbing and non-absorbing aerosols retrieved by cavity ring down (CRD) spectroscopy, Atmos. Chem. Phys., 7, 15231536, doi:10.5194/acp-7-1523-2007, 2007.

Adler, G., Koop, T., Haspel, C., Taraniuk, I., Moise, T., Koren, I., Heiblum, R. H., and Rudich, Y.: Formation of highly porous aerosol particles by atmospheric freeze-drying in ice clouds, Proc. Natl. Acad. Sci. USA, 110, 20414-20419, doi:10.1073/pnas.1317209110, 2013.

Adler, G., Haspel, C., Moise, T., and Rudich, Y.: Optical extinction of highly porous aerosol following atmospheric freeze drying, J. Geophys. Res.-Atmos., 119, 6768-6787, doi:10.1002/2013JD021314, 2014.

Allen, A. G., Mather, T. A., McGonigle, A. J. S., Aiuppa, A., Delmelle, P., Davison, B., Bobrowski, N., Oppenheimer, C., Pyle, D. M., and Inguaggiato, S.: Sources, size distribution, and downwind grounding of aerosols from Mount Etna, J. Geophys. Res.-Atmos., 111, D10302, doi:10.1029/2005JD006015, 2006.

Ammann, M. and Burtscher, H.: Characterization of ultrafine aerosol particles in Mt. Etna emissions, Bull. Volcanol., 52, 577583, doi:10.1007/BF00301209, 1990. 
Baumgardner, D., Dye, J. E., Gandrup, B. W., and Knollenberg, R. G.: Interpretation of measurements made by the Forward Scattering Spectrometer Probe (FSSP-300) during the Airborne Arctic Stratosphere Expedition, J. Geophys. Res.-Atmos., 97, 80358046, doi:10.1029/91JD02728, 1992.

Chýlek, P., Srivastava, V., Pinnick, R. G., and Wang, R.: Scattering of electromagnetic waves by composite spherical particles: Experiment and effective medium approximation, Appl. Optics, 27, 2396-2404, doi:10.1364/AO.27.002396, 1988.

Chýlek, P., Videen, G., Geldart, D. J. W., Dobbie, J. S., and Tso, H. C. W.: Effective medium approximations for heterogeneous particles, in: Light scattering by nonspherical particles, theory, measurements, and applications, edited by: Mishchenko, M. I., Hovenier, J. W., and Travis, L. D., Academic Press, 273-308, 2000.

Delmelle, P.: Environmental impacts of tropospheric volcanic gas plumes, in: Volcanic degassing, edited by: Oppenheimer, C., Pyle, D. M., and Barclay, J., Geol. Soc. London Special Publ., 213, 381-399, doi:10.1144/GSL.SP.2003.213.01.23, 2003

Dick, W. D., Ziemann, P. J., Huang, P.-F., and McMurry, P. H.: Optical shape fraction measurements of submicrometre laboratory and atmospheric aerosols, Meas. Sci. Technol., 9, 183-196, doi:10.1088/0957-0233/9/2/006, 1998.

Dubovik, O., Sinyuk, A., Lapyonok, T., Holben, B. N., Mishchenko, M., Yang, P., Eck, T. F., Volten, H., Muñoz, O., Veihelmann, B., van der Zande, W. J., Leon, J.-F., Sorokin, M., and Slutsker, I.: Application of spheroid models to account for aerosol particle nonsphericity in remote sensing of desert dust, J. Geophys. Res.Atmos., 111, D11208, doi:10.1029/2005JD006619, 2006.

Dubovik, O., Herman, M., Holdak, A., Lapyonok, T., Tanré, D., Deuzé, J. L., Ducos, F., Sinyuk, A., and Lopatin, A.: Statistically optimized inversion algorithm for enhanced retrieval of aerosol properties from spectral multi-angle polarimetric satellite observations, Atmos. Meas. Tech., 4, 975-1018, doi:10.5194/amt-4975-2011, 2011.

Dye, J. E. and Baumgardner, D.: Evaluation of the forward scattering spectrometer probe, I - Electronic and optical studies, J. Atmos. Ocean. Tech., 1, 329-344, doi:10.1175/15200426(1984)001<0329:EOTFSS>2.0.CO;2, 1984.

Eck, T. F., Holben, B. N., Reid, J. S., Sinyuk, A., Dubovik, O., Smirnov, A., Giles, D., O’Neill, N. T., Tsay, S.-C., Ji, Q., Al Mandoos, A., Ramzan Khan, M., Reid, E. A., Schafer, J. S., Sorokine, M., Newcomb, W., and Slutsker, I.: Spatial and temporal variability of column-integrated aerosol optical properties in the southern Arabian Gulf and United Arab Emirates in summer, J. Geophys. Res. Atmos., 113, D01204, doi:10.1029/2007JD008944, 2008

Febvre, G., Gayet, J.-F., Shcherbakov, V., Gourbeyre, C., and Jourdan, O.: Some effects of ice crystals on the FSSP measurements in mixed phase clouds, Atmos. Chem. Phys., 12, 8963-8977, doi:10.5194/acp-12-8963-2012, 2012.

Frey, W., Borrmann, S., Kunkel, D., Weigel, R., de Reus, M., Schlager, H., Roiger, A., Voigt, C., Hoor, P., Curtius, J., Krämer, M., Schiller, C., Volk, C. M., Homan, C. D., Fierli, F., Di Donfrancesco, G., Ulanovsky, A., Ravegnani, F., Sitnikov, N. M., Viciani, S., D’Amato, F., Shur, G. N., Belyaev, G. V., Law, K. S., and Cairo, F.: In situ measurements of tropical cloud properties in the West African Monsoon: upper tropospheric ice clouds, Mesoscale Convective System outflow, and subvisual cirrus, At- mos. Chem. Phys., 11, 5569-5590, doi:10.5194/acp-11-55692011, 2011.

Fulignati P., Sbrana, A., Clocchiatti, R., and Luperini, W.: Environmental impact of the acid fumarolic plume of a passively degassing volcano (Vulcano Island, Italy), Environ. Geol., 49, 1139-1155, doi:10.1007/s00254-005-0158-0, 2006.

Gayet, J.-F., Crépel, O., Fournol, J.-F., and Oshchepkov, S.: A new airborne polar Nephelometer for the measurements of optical and microphysical cloud properties. Part I: Theoretical design, Ann. Geophys., 15, 451-459, doi:10.1007/s00585-997-0451-1, 1997.

Gayet, J.-F., Asano, S., Yamazaki, A., Uchiyama, A., Sinyuk, A., Jourdan, O., and Auriol, F.: Two case studies of winter continental-type water and mixed-phase stratocumuli over the sea: 1. Microphysical and optical properties, J. Geophys. Res., 107, 4569, doi:10.1029/2001JD001106, 2002.

Gayet, J.-F., Shcherbakov, V., Voigt, C., Schumann, U., Schäuble, D., Jessberger, P., Petzold, A., Minikin, A., Schlager, H., Dubovik, O., and Lapyonok, T.: The evolution of microphysical and optical properties of an A380 contrail in the vortex phase, Atmos. Chem. Phys., 12, 6629-6643, doi:10.5194/acp-12-66292012, 2012.

Gosse, S. F., Wang, M., Labrie, D., and Chylek, P.: Imaginary part of the refractive index of sulfates and nitrates in the 0.7-2.6 $\mu \mathrm{m}$ spectral region, Appl. Optics, 36, 3622-3634, doi:10.1364/AO.36.003622, 1997.

Hansen, P. C.: Analysis of discrete ill-posed problems by means of the L-curve, SIAM Rev., 34, 561-580, doi:10.1137/1034115, 1992.

Heiken, G. and Wohletz, K.: Volcanic Ash, Univ. of Calif. Press, Berkeley, 246 pp., 1985.

Jaenicke, R. and Hanusch, T.: Simulation of the Optical Particle Counter Forward Scattering Spectrometer Probe 100 (FSSP-100), Aerosol Sci. Tech., 18, 309-322, doi:10.1080/02786829308959607, 1993.

Jeong, G. Y. and Nousiainen, T.: TEM analysis of the internal structures and mineralogy of Asian dust particles and the implications for optical modeling, Atmos. Chem. Phys., 14, 7233-7254, doi:10.5194/acp-14-7233-2014, 2014.

Jeßberger, P., Voigt, C., Schumann, U., Sölch, I., Schlager, H., Kaufmann, S., Petzold, A., Schäuble, D., and Gayet, J.-F.: Aircraft type influence on contrail properties, Atmos. Chem. Phys., 13, 11965-11984, doi:10.5194/acp-13-11965-2013, 2013.

Johnson, R. A. and Wichern, D. J.: Applied multivariate statistical analysis, 4th Edn., Prentice hall Inc, New Jersey, 816 pp., 1998.

Jolliffe, I. T.: Principal Component Analysis, Series: Springer Series in Statistics, 2nd Edn., Springer, NY, 487 p., 2002.

Jourdan, O., Oshchepkov, S., Gayet, J.-F., Shcherbakov, V., and Isaka, H.: Statistical analysis of cloud light scattering and microphysical properties obtained from airborne measurements, J. Geophys. Res., 108, 4155, doi:10.1029/2002JD002723, 2003.

Jourdan, O., Mioche, G., Garret, T. J., Schwarzenbock, A., Vidot, J., Xie, Y., Shcherbakov, V., Duroure, C., Yang, P., and Gayet, J.-F.: Coupling of the microphysical and optical properties of arctic clouds during the ASTAR 2004 experiment: Implications for light scattering modelling, J. Geophys. Res., 115, D23206, doi:10.1029/2010JD014016, 2010.

Jurkat, T., Voigt, C., Arnold, F., Schlager, H., Aufmhoff, H., Schmale, J., Schneider, J., Lichtenstern, M., and Dörnbrack, A.: Airborne stratospheric ITCIMS-measurements of $\mathrm{SO}_{2}, \mathrm{HCl}$, and 
$\mathrm{HNO}_{3}$ in the aged plume of volcano Kasatochi, J. Geophys. Res., 115, D00L17, doi:10.1029/2010JD013890, 2010.

Jurkat, T., Voigt, C., Arnold, F., Schlager, H., Kleffmann, J., Aufmhoff, H., Schäuble, D., Schaefer, M., and Schumann, U.: Measurements of $\mathrm{HONO}, \mathrm{NO}, \mathrm{NO}_{y}$ and $\mathrm{SO}_{2}$ in aircraft exhaust plumes at cruise, Geophys. Res. Lett., 38, L10807, doi:10.1029/2011GL046884, 2011.

Jurkat, T., Kaufmann, S., Voigt, C., Schäuble, D., Jeßberger, P., and Ziereis, H.: The airborne mass spectrometer AIMS - Part 2: Measurements of trace gases with stratospheric or tropospheric origin in the UTLS, Atmos. Meas. Tech., 9, 1907-1923, doi:10.5194/amt-9-1907-2016, 2016.

Kahn, R. A., Li, W.-H., Moroney, C., Diner, D. J., Martonchik, J. V., and Fishbein, E.: Aerosol source plume physical characteristics from space-based multiangle imaging, J. Geophys. Res., 112, D11205, doi:10.1029/2006JD007647, 2007.

Kaufmann, S., Voigt, C., Jeßberger, P., Jurkat, T., Schlager, H., Schwarzenboeck, A., Klingebiel, M., and Thornberry, T.: In situ measurements of ice saturation in young contrails, Geophys. Res. Lett., 41, 702-709, doi:10.1002/2013GL058276, 2014.

Kaufmann, S., Voigt, C., Jurkat, T., Thornberry, T., Fahey, D. W., Gao, R.-S., Schlage, R., Schäuble, D., and Zöger, M.: The airborne mass spectrometer AIMS - Part 1: AIMS- $\mathrm{H}_{2} \mathrm{O}$ for UTLS water vapor measurements, Atmos. Meas. Tech., 9, 939-953, doi:10.5194/amt-9-939-2016, 2016.

Kitamura, R., Pilon, L., and Jonasz, M.: Optical constants of silica glass from extreme ultraviolet to far infrared at near room temperature, Appl. Optics, 46, 8118-8133, doi:10.1364/AO.46.008118, 2007.

Kolokolova L. and Gustafson, B. A. S.: Scattering by inhomogeneous particles: microwave analog experiments and comparison to effective medium theories, J. Quant. Spectrosc. Ra., 70, 61125, doi:10.1016/S0022-4073(01)00033-4, 2001.

Kylling, A., Kahnert, M., Lindqvist, H., and Nousiainen, T.: Volcanic ash infrared signature: porous non-spherical ash particle shapes compared to homogeneous spherical ash particles, Atmos. Meas. Tech., 7, 919-929, doi:10.5194/amt-7-919-2014, 2014.

Lefevre, R., Gaudichet, A., and Billongalland, M. A.: Silicate microspherules intercepted in the plume of Etna volcano, Nature, 322, 817-820, doi:10.1038/322817a0, 1986.

Li, H. H.: Refractive index of alkali halides and its wavelength and temperature derivatives, J. Phys. Chem. Ref. Data, 5, 329-528 doi:10.1063/1.555536, 1976.

Lide, D. R. (Ed.): CRC Handbook of Chemistry and Physics, 90th Edn., CRC Press, 2010.

Liu, C., Lee Panetta, R., and Yang,P. : Inhomogeneity structure and the applicability of effective medium approximations in calculating light scattering by inhomogeneous particles, J. Quant. Spectrosc. Ra., 146, 331-348, doi:10.1016/j.jqsrt.2014.03.018, 2014.

Marenco, F., Johnson, B., Turnbull, K., Newman, S., Haywood, J., Webster, H., and Ricketts, H.: Airborne lidar observations of the 2010 Eyjafjallajökull volcanic ash plume, J. Geophys. Res., 116, D00U05, doi:10.1029/2011JD016396, 2011.

Martin, R. S., Mather, T. A., Pyle, D. M., Power, M., Allen, A. G., Aiuppa, A., Horwell, C. J., and Ward, E. P. W.: Composition-resolved size distributions of volcanic aerosols in the Mt. Etna plumes, J. Geophys. Res., 113, D17211, doi:10.1029/2007JD009648, 2008.
Martin, R. S., Mather, T. A., Pyle, D. M., Power, M., Tsanev, V. I., Oppenheimer, C., Allen, A. G., Horwell, C. J., and Ward, E. P. W.: Size distributions of fine silicate and other particles in Masaya's volcanic plume, J. Geophys. Res., 114, D09217, doi:10.1029/2008JD011211, 2009.

Martin, S. T.: Phase transitions of aqueous atmospheric particles, Chem. Rev., 100, 3403-3454, doi:10.1021/cr990034t, 2000.

Mather, T. A., Pyle, D. M., and Oppenheimer, C.: Tropospheric Volcanic Aerosol, in: Volcanism and the Earth's Atmosphere, edited by: Robock, A. and Oppenheimer, C., American Geophysical Union, Washington, DC, doi:10.1029/139GM12, 2004.

Maxwell Garnett, J. C.: Colours in metal glasses and in metallic films, Philos. Trans. Roy. Soc. A, 203, 385-420, doi:10.1098/rsta.1904.0024, 1904.

Mishchenko, M. I., Travis, L. D., Kahn, R. A., and West, R. A.: Modeling phase functions for dustlike tropospheric aerosols using a mixture of randomly oriented polydisperse spheroids, J. Geophys. Res., 102, 16831-16847, doi:10.1029/96JD02110, 1997.

Mishchenko, M. I., Wiscombe, W. J., Hovenier, J. W., and Travis, L. D.: Overview of scattering by nonspherical particles, in: Light Scattering by Nonspherical Particles, edited by: Mishchenko, M. I., Hovenier, J. W., and Travis, L. D., Academic Press, San Diego, CA, USA, chap. 2, 29-60, 2000.

Mishchenko, M. I., Dlugach, J. M., Yurkin, M. A., Bi, L., Cairns, B., Liu, L., Panetta, R. L., Travis, L. D., Yang, P., and Zakharova, N. T.: First-principles modeling of electromagnetic scattering by discrete and discretely heterogeneous random media, Phys. Rep., 632, 1-75, doi:10.1016/j.physrep.2016.04.002, 2016.

Nousiainen, T.: Optical modeling of mineral dust particles: A review. J. Quant. Spectrosc. Ra., 110, 1261-1279, doi:10.1016/j.jqsrt.2009.03.002, 2009.

Obenholzner, J. H., Schroettner, H., Golob, P., and Delgado, H.: Particles from the plume of Popocatepetl volcano, Mexico - the FESEM/EDS approach, in: Volcanic degassing, edited by: Oppenheimer, C., Pyle, D. M., and Barclay, J., Geol. Soc. London Special Publ., 213, 123-148, doi:10.1144/GSL.SP.2003.213.01.08, 2003.

Oppenheimer, C., Scaillet, B., and Martin, R. S.: Sulfur degassing from volcanoes: source conditions, surveillance, plume chemistry and Earth system impacts, Rev. Mineral. Geochem., 73, 363-421, doi:10.2138/rmg.2011.73.13, 2011.

Petzold, A., Busen, R., Schröder, F. P., Baumann, R., Kuhn, M., Ström, J., Hagen, D. E., Whitefield, P. D., Baumgardner, D., Arnold, F., Borrmann, S., and Schumann, U.: Nearfield measurements on contrail properties from fuels with different sulfur content, J. Geophys. Res., 102, 29867-29880, doi:10.1029/97JD02209, 1997.

Pinnick, R. G. and Auvermann, H. J.: Response Characteristics of Knollenberg Light-Scattering Aerosol Counters, J. Aerosol Sci., 10, 55-74, doi:10.1016/0021-8502(79)90015-6, 1979.

Pósfai, M., Anderson, J. R., Buseck, P. R., and Sievering, H.: Soot and sulfate aerosol particles in the remote marine troposphere, J. Geophys. Res., 104, 21685-21693, doi:10.1029/1999JD900208, 1999.

Schmidt, A., Carslaw, K. S., Mann, G. W., Rap, A., Pringle, K. J., Spracklen, D. V., Wilson, M., and Forster, P. M.: Importance of tropospheric volcanic aerosol for indirect radiative forcing of cli- 
mate, Atmos. Chem. Phys., 12, 7321-7339, doi:10.5194/acp-127321-2012, 2012.

Scollo, S., Kahn, R. A., Nelson, D. L., Coltelli, M., Diner, D. J., Garay, M. J., and Realmuto, V. J.: MISR observations of Etna volcanic plumes, J. Geophys. Res., 117, D06210, doi:10.1029/2011JD016625, 2012.

Shcherbakov V., Gayet, J.-F., Jourdan, O., Minikin, A., Ström, J., and Petzold, A.: Assessment of cirrus cloud optical and microphysical data reliability by applying statistical procedures, J. Atmos. Ocean. Tech., 22, 409-420, doi:10.1175/JTECH1710.1, 2005.

Shcherbakov, V., Gayet, J.-F., Baker, B. A., and Lawson, R. P.: Light scattering by single natural ice crystals, J. Atmos. Sci., 63, 15131525, doi:10.1175/JAS3690.1, 2006.

Spinetti, C., Buongiorno, M. F., Lombardo, V., and Merucci, L.: Aerosol optical thickness of Mt. Etna volcanic plume retrieved by means of the Airborne Multispectral Imaging Spectrometer (MIVIS), Ann. Geophys., 46, 439-449, doi:10.4401/ag-3417, 2003.

Tang, I. N.: Chemical and size effects of hygroscopic aerosols on light scattering coefficients, J. Geophys. Res., 101, 1924519250, doi:10.1029/96JD03003, 1996.

Tang, I. N. and Munkelwitz, H. R.: Simultaneous Determination of Refractive Index and Density of an Evaporating Aqueous Solution Droplet, Aerosol Sci. Tech., 15, 201-207, doi:10.1080/02786829108959527, 1991.

Toledano, C., Bennouna, Y., Cachorro, V., Ortiz de Galisteo, J. P., Stohl, A., Stebel, K., Kristiansen, N. I., Olmo, F. J., Lyamani, H., Obregón, M. A., Estellés, V., Wagner, F., Baldasano, J. M., González-Castanedo, V, Clarisse, L., and de Frutos, A. M.: Aerosol properties of the Eyjafjallajökull ash derived from sun photometer and satellite observations over the Iberian Peninsula, Atmos. Environ., 48, 22-32, doi:10.1016/j.atmosenv.2011.09.072, 2012.

Toon, O. B., Pollack, J. B., and Khare, B. N.: The optical constants of several atmospheric aerosol species: ammonium sulfate, aluminum oxide, and sodium chloride, J. Geophys. Res., 81, 57335748, doi:10.1029/JC081i033p05733, 1976.

Ulanowski, Z. and Schnaiter, M.: UV and visible light scattering and absorption measurements on aerosols in the laboratory, in: Fundamentals and Applications of Aerosol Spectroscopy, edited by: Reid, J. P. and Signorell, R., CRC Press, Boca Raton, 243268, doi:10.1201/b10417-14, 2011.

Verhaege, C., Shcherbakov, V., and Personne, P.: Limitations on retrieval of complex refractive index of spherical particles from scattering measurements, J. Quant. Spectrosc. Ra., 109, 2338 2348, doi:10.1016/j.jqstr.2008.05.009, 2008.
Voigt, C., Schumann, U., Jurkat, T., Schäuble, D., Schlager, H., Petzold, A., Gayet, J.-F., Krämer, M., Schneider, J., Borrmann, S., Schmale, J., Jessberger, P., Hamburger, T., Lichtenstern, M., Scheibe, M., Gourbeyre, C., Meyer, J., Kübbeler, M., Frey, W., Kalesse, H., Butler, T., Lawrence, M. G., Holzäpfel, F., Arnold, F., Wendisch, M., Döpelheuer, A., Gottschaldt, K., Baumann, R., Zöger, M., Sölch, I., Rautenhaus, M., and Dörnbrack, A.: In-situ observations of young contrails - overview and selected results from the CONCERT campaign, Atmos. Chem. Phys., 10, 90399056, doi:10.5194/acp-10-9039-2010, 2010.

Voigt, C., Schumann, U., Jessberger, P., Jurkat, T., Petzold, A., Gayet, J.-F., Krämer, M., Thornberry, T., and Fahey, D. W.: Extinction and optical depth of contrails, Geophys. Res. Lett., 38, L11806, doi:10.1029/2011GL047189, 2011.

Voigt, C., Jessberger, P., Jurkat, T., Kaufmann, S., Baumann, R., Schlager, H., Bobrowski, N., Giuffrida, G., and Salerno, G.: Evolution of $\mathrm{CO}_{2}, \mathrm{SO}_{2}, \mathrm{HCl}$, and $\mathrm{HNO}_{3}$ in the volcanic plumes from Etna, Geophys. Res. Lett., 41, 2196-2203, doi:10.1002/2013GL058974, 2014a.

Voigt, C., Jeßberger, P., Jurkat, T., Kaufmann, S., Baumann, R., Schlager, H., Bobrowski, N., Guffirda, G., and Salerno, G.: Reply to comment from Liotta and Rizzo, B. Volcanol., 76, 865, doi:10.1007/s00445-014-0865-z, 2014b.

Voshchinnikov, N., Videen, G., and Henning, T.: Effective medium theories for irregular fluffy structures: aggregation of small particles, Appl. Optics, 46, 4065-4072, doi:10.1364/AO.46.004065, 2007.

Waquet, F., Peers, F., Goloub, P., Ducos, F., Thieuleux, F., Derimian, Y., Riedi, J., Chami, M., and Tanré, D.: Retrieval of the Eyjafjallajökull volcanic aerosol optical and microphysical properties from POLDER/PARASOL measurements, Atmos. Chem. Phys., 14, 1755-1768, doi:10.5194/acp-14-1755-2014, 2014.

Watson, I. M. and Oppenheimer, C.: Particle size distributions of Mount Etna's aerosol plume constrained by Sun photometry, J. Geophys. Res., 105, 9823-9829, doi:10.1029/2000JD900042, 2000.

Watson, I. M. and Oppenheimer, C.: Photometric observations of Mt. Etna's different aerosol plumes, Atmos. Environ., 35, 35613572, doi:10.1016/S1352-2310(01)00075-9, 2001.

Yang, P., Bi, L., Baum, B. A., Liou, K.-N., Kattawar, G. W., Mishchenko, M. I., and Cole, B.: Spectrally Consistent Scattering, Absorption, and Polarization Properties of Atmospheric Ice Crystals at Wavelengths from 0.2 to $100 \mu \mathrm{m}$, J. Atmos. Sci., 70, 330-347, doi:10.1175/JAS-D-12-039.1, 2013.

Young, C. L., Sokolik, I. N., and Dufek, J.: Regional radiative impact of volcanic aerosol from the 2009 eruption of Mt. Redoubt, Atmos. Chem. Phys., 12, 3699-3715, doi:10.5194/acp-12-36992012, 2012. 